TANGIBLE CULTURAL ANALYTICS:

\title{
HOW TANGIBLE AUGNMENTED REALITY CAN ENHANCE CULTURAL HERITAGE RESEARCH
}

\author{
by \\ Daniella Kalinda \\ Psychology, BSc, University of Toronto, 2018
}

\author{
A Major Research Project \\ presented to Ryerson University \\ in partial fulfillment of the \\ requirements for the degree \\ of Master of Digital Media
}

in the program of Digital Media

Toronto, Ontario, Canada, 2019

(C) Daniella Kalinda, 2019 


\section{Author's Declaration for Electronic Submission of an MRP}

I hereby declare that I am the sole author of this MRP. This is a true copy of the MRP, including any required final revisions.

I authorize Ryerson University to lend this MRP to other institutions or individuals for the purpose of scholarly research.

I further authorize Ryerson University to reproduce this MRP by photocopying or by other means, in total or in part, at the request of other institutions or individuals for the purpose of scholarly research.

I understand that my MRP may be made electronically available to the public. 


\section{Abstract}

How do we explore history in a new way? Current digitization and archival methods do not have the richness and versatility necessary for researching cultural heritage. In this paper, the role of augmented reality in cultural heritage research is investigated. Then, a formative study is described and analyzed to gain an understanding of the workflow, desired insights and reported pain points that scholars face when working with cultural heritage collections. Finally, the findings from this study are used to propose design concepts for an augmented reality prototype for searching within a collection of artifacts and visualizing selected artifacts. In conclusion, possible directions for the potential of augmented reality in cultural heritage are discussed. 


\section{Acknowledgments}

I would like to thank my father and mother whose belief in me and unconditional support has given me the strength and vision to want to contribute good things in the world...and thank you to my siblings because laughter is how we do life. Thank you, also, to my uncle, Umu, who read each line, commented and helped me find structure with all my many ideas.

I would also like to thank my supervisor, Dr. Ali Mazalek, your unquenching curiosity and hope about all the possibilities in experiential design makes working in your lab fun and innovative. Thank you also to my second reader, Steve Cober. Your approach to design and generosity in teaching is something I'm grateful for and admire.

Finally, I would also like to thank Ravit David and Brock Silverslides from the Thomas Fisher Library. Thank you for sharing your special collection with the Synaesthetic Media Lab and collaborating with us to make research more intuitive, more interactive, more dynamic 


\section{Table of Contents}

Author's Declaration for Electronic Submission of an MRP .................................................. ii

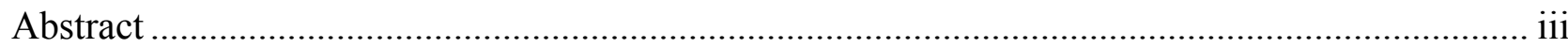

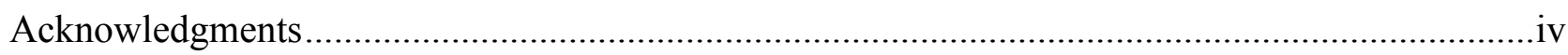

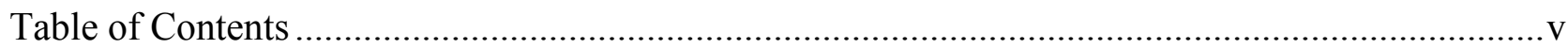

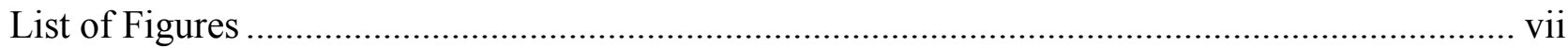

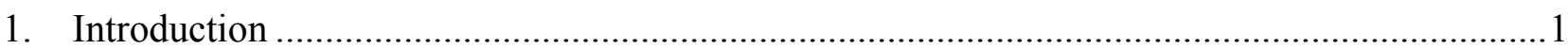

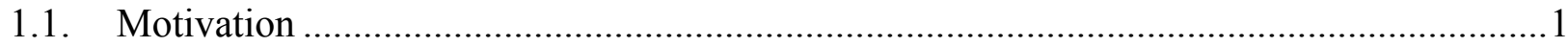

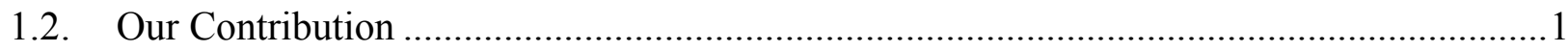

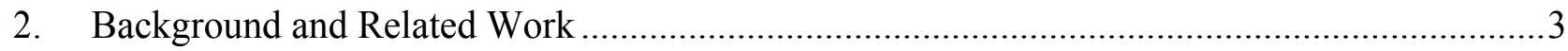

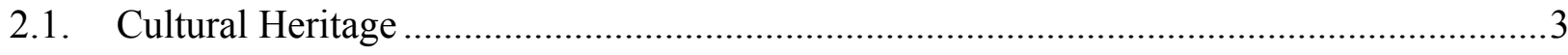

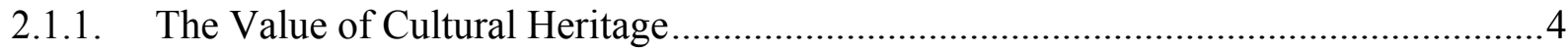

2.1.2. The Challenges of Cultural Heritage ....................................................................

2.1.3. An Initiative for Cultural Heritage ...............................................................

2.2. Innovative Uses of Technology in Cultural Heritage ...............................................5

2.2.1. Enhanced Museum Experiences ................................................................ 6

2.2.2. Augmented Reality in Cultural Heritage ........................................................

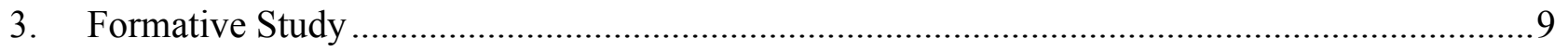




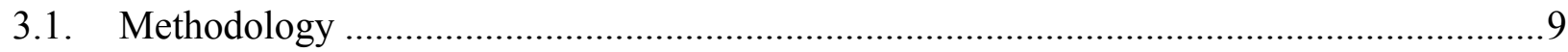

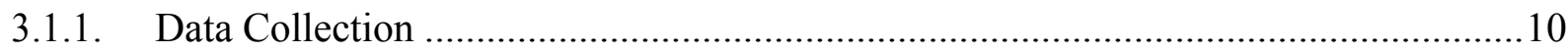

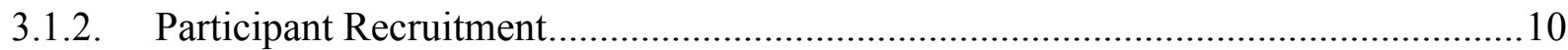

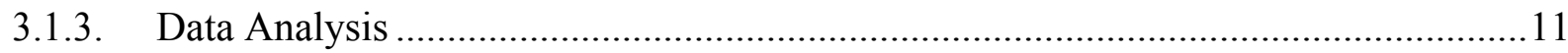

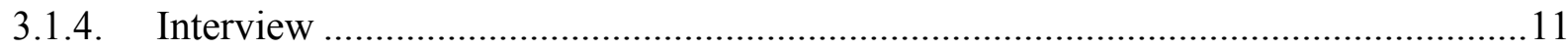

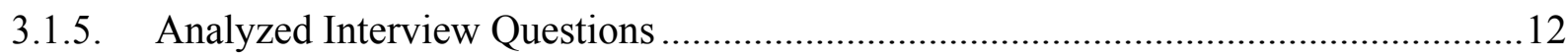

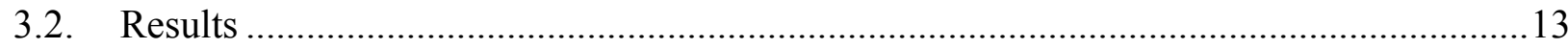

3.2.1. Research Workflow: Advantages and Disadvantages...............................................13

3.2.2. Tangible Search versus Digital Search: Advantages and Disadvantages ....................15

3.2.3. Reported Possible Solutions for Current Pain Points...................................................17

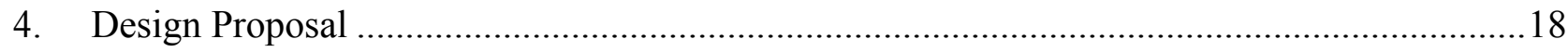

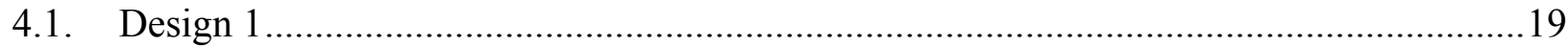

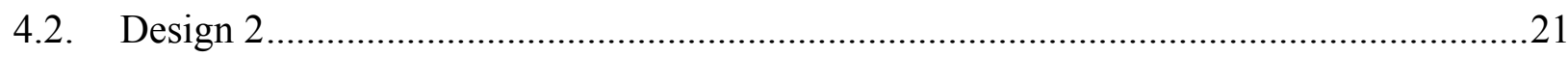

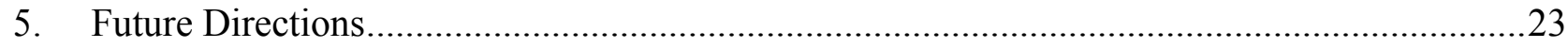

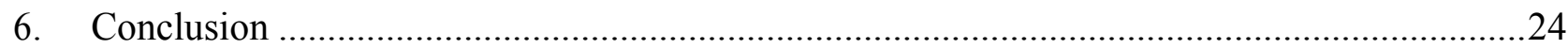

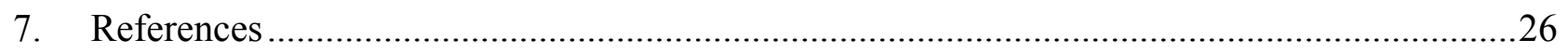

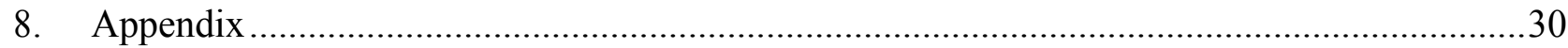

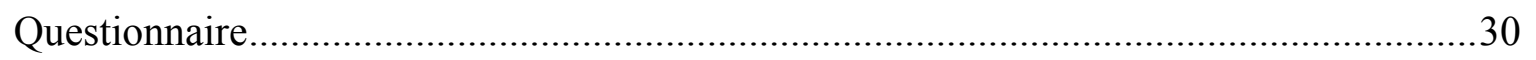




\section{List of Figures}

$\begin{array}{ll}\text { Figure 1: Interactive Cube AR App Design } & 20\end{array}$

Figure 2: ‘Annexing Reality’ Style AR App Design

Figure 3: Interactive Cube with Artifact

Figure 4: Artifact Switching and Description

Figure 5: Interactions with Application 


\section{Introduction}

The field of cultural heritage is showing a lot of promise with the advancement of technology. The preservation of these items may not have to only rely on climate-controlled archives and limited access to researchers. With the bridging of the physical and digital world that has been made possible through the human computer interaction field, technologies such as augmented reality, virtual reality and mixed reality offer new possibilities not only for technological enthusiasts but for all kinds of domains. The rise in popularity of augmented reality, in particular, is showing promise for the integration of this kind of technology for people of all walks of life--even scholars of history.

\subsection{Motivation}

In this paper, I will investigate the field of cultural heritage and how innovative technologies, particularly augmented reality, have been used to keep the field relevant in a highly digitized era. I will describe the value and challenges of working with primary source cultural heritage, then I will describe the strides in digital recreations of accessing cultural heritage. I will also describe the formative study we undertook to understand the pain points in cultural heritage research, as well as to understand the current practices in research and the kinds of insights sought from physical cultural heritage items. I then propose two designs based on the analysis of the data from the formative study. Finally, I conclude with possible directions for the integration of augmented reality in cultural heritage research.

\subsection{Our Contribution}

The Tangible Cultural Analytics project was taken as part of a group Major Research Project with Ben Ashley, Zeeanna Ibrahim, and myself, Daniella Kalinda. Each person contributed their own part as part of the greater project. These will be briefly described below: 
Ben's contribution was creating a relevant recommender system while searching and analyzing artifacts within the augmented reality application. Recommender systems use metadata attributes to find common themes between similar items and group them together (Boehmer, 2015). Ben's project discusses how recommender systems can be applied to cultural heritage research. He decided on a content-based recommender system without a user profile would work best. For the prototype, he developed an equation that compares objects against each other and gives a relevance percentage. The percentages are then ranked and the top four would be recommended in the application. He also discusses how future iterations could include a rating system, user profiles, and machine learning.

Zeanna contributed in the user experience of the application. Effective user experience depends on multiple factors such as accurate information, approach to design, and the methods followed (Adikari, 2013). The principles of design thinking were used to iteratively design and deploy the prototype. From a literature search and the formative study, we found the main challenges to address were low access to cultural heritage online, the mis-cataloguing of online data, and time and budget constraints in visiting archives. This mobile prototype aims to reflect the actions and occurrences practiced in research as features in the app. She used the wireframes to create an interactive user experience that integrates with the augmented reality display. So, the augmented reality application aimed to address some of these issues. Namely, providing high quality images of artifacts and using an interactive paper cube to activate the artifacts. This aims to help researchers decide whether to make the archival visit.

I, Daniella, contributed in the research and preliminary design of the application. Since museums and other cultural heritage sites are using augmented reality to increase destination visit intentions and purchase intentions ( $\mathrm{He}, \mathrm{Wu}$ and $\mathrm{Li}, 2018)$, I proposed augmented reality could be used in a similar way when heritage scholars are researching heritage items and still deciding whether or not to visit an archive. I helped conduct interviews and analyzed the results to help design a tangible augmented reality experience for research. By creating simple wireframes, we worked as a group to iteratively create a simple augmented reality application for researchers. 
This paper seeks to contribute practical ways that augmented reality can be integrated in the research process. It explores the digitization of cultural heritage and discusses how introducing augmented reality to cultural heritage research can help improve both the study and the digitization of archival items.

\section{Background and Related Work}

In this section, the role and value of cultural heritage is discussed. Then, the innovations in museum experiences are investigated. Finally, the role of augmented reality is discussed as its own platform and its integration in the heritage tourism industry. This leads to a design proposal for an augmented reality application for cultural heritage research.

\subsection{Cultural Heritage}

The preservation of history has been an important part of society for a long time. Traditions are passed down from one generation to another through stories, practices, norms, and physical items. Cultural heritage, therefore, refers to the material or immaterial objects, artifacts, practices or norms of a group from a particular time in society considered valuable sources of history (Brumann, 2015). The material objects can vary from three-dimensional, such as artifacts, or paper-based items known as ephemera. Ephemera refers to the collections of printed materials created for a specific and transient purpose, including flyers, diaries, and printed calendars. The term ephemera originally means 'diary' or 'calendar' (Anghelescu, 2001). They offer first-person access to the item's original historical context. Thus, avoiding the bias of interpretation, and providing a context that inspires new questions and creative thinking. Both artifacts and ephemera are part of the larger literature on cultural heritage, along with other primary source articles from archival documents to archaeological sites and ruins. The preservation of cultural heritage is valuable in a society as it helps one generation communicate with another across time. 


\subsubsection{The Value of Cultural Heritage}

Both the general public and academic researchers alike seek out cultural heritage. First-hand public access to cultural heritage, however, is limited by several factors. For travel and tourism, cultural heritage centres are trying to increase their number of visitors, improve the visitor experience, and reimagine public perception of cultural heritage sites as exciting, innovative and entertaining (Chung, Han and Joun, 2015). One of the ways the industry has achieved this is by incorporating emerging technology as part of the visitor experience. Specifically, augmented reality.

The methodology for preserving cultural heritage has evolved with the advancement of technology. In recent history, the digitization of cultural heritage, specifically archival documents have increased. As it is, many libraries are taking initiatives to digitize their collection to increase access to their wealth of historical items, remain relevant in a digital world, and to keep the library as the center for knowledge acquisition (Jones, 2017). This, however, comes with its own set of challenges.

\subsubsection{The Challenges of Cultural Heritage}

Ephemera are most meaningfully understood in a collection (Anghelescu, 2001). For example, an individual postcard starting with the name John may not illustrate the need for privacy and identity protection in concentration camps but numerous postcards of the same name can indicate the use of aliases. That collection of postcards, however, can reveal the declining hope of prisoners escaping concentration camps. Therefore, the collective value of ephemera makes them both unique and difficult to work with since libraries receive very varied special collections on a bydonation basis.

Donated special collections are often miscellaneous depending on the donor's intention. The items

of a collection may have been randomly assorted in a scrapbook, carefully selected by an experienced collector, or inherited by a family member. With the shortage of space in libraries and the oft-inefficient visit by researchers to the archives, various libraries have created initiatives to 
remain relevant as a center of knowledge acquisition and research in a highly digitized era (Anghelescu, 2001). Librarians and archivists also struggle to classify these special collections in a meaningful way that supports the research process. While a collection can provide valuable insights on a collector and the motivations behind the collections, more often than not, however, these decisions appear to be arbitrary. Part of a cultural scholar's research process is making sense of the authenticity of a collection and interpreting how it was catalogued.

\subsubsection{An Initiative for Cultural Heritage}

Various libraries have taken the initiative to digitize their archives (Smith, 2016). In Toronto, the Thomas Fisher Rare Book Library in Toronto, as part of the Mernick Farley collection of Jewish ephemera, is seeking to digitize its collection in an innovative way that helps cultural scholars with the insightful research of primary source cultural heritage from remote places. The Tangible Cultural Analytics project is being conducted in partnership with this initiative. The goal is to create intuitive and engaging interfaces for meaningful digital research experiences. In order to do so, we investigated ways that innovative technologies have been used for the dissemination and preservation of cultural heritage.

\subsection{Innovative Uses of Technology in Cultural Heritage}

This section will investigate the use of innovative technologies in cultural heritage. It will investigate ways that museums have enhanced their visitor experience. Then it will show applications of virtual reality for cultural heritage. It will then demonstrate how augmented reality can be used in cultural heritage research by discussing its effectiveness in training and education, as well as tourism for cultural heritage. This will lead to the introduction of the formative study of cultural scholars' interviews. 


\subsubsection{Enhanced Museum Experiences}

Museums offer the general public with access to history. Visitors come to be inspired, experience art and culture, and gain a better understanding of discovered phenomena. With the information overload people experience both online and offline, visitors tend to have shorter attention spans and enjoy the museum experience less (Benouaret and Lenne, 2015). Curators have had to be more innovative in engaging today's visitor. Researchers and designers have also had to adapt how they represent cultural heritage in order to sustain the tradition and, alas, meaning behind it. In South Africa, researchers joined the BaNtwane tribe to help digitize their oral history. By iteratively designing with the expert users of the community, they created 'StoryBeads' - a recording device within a traditional beaded necklace that records elders as they tell stories (Reitsma, Smith and van den Hoven, 2013). This helped the community to maintain its oral tradition and, as part of a museum display, has given the tribe widespread access to a larger public community.

In Canada and the United States, researchers created a preservation-driven interactive storytelling application called 'Mapping Place' (Chu, Clifton, Harley, Pavao and Mazalek, 2015). Visitors can connect virtual story beads on the multi-touch tabletop to tangible shells in their hands. Each person can construct their own stories - keeping with the tradition of the Lukasa boards. This cocreation process is not only engaging for visitors but allows for more meaningful storytelling. Other researchers prototyped three-dimensional replicas of sixteenth century prayer nutsspherical wooden objects with Christian iconographic engravings used for spiritual devotion (Kwan, Chu, Harley, McBride and Mazalek, 2016). To ensure realistic interactions with the replica, there were tactile, visual, auditory and fragrant touchpoints for the visitor to engage with. This experience immersed visitors in the experience of the artifact that goes beyond a simple

description. These kinds of experiences have helped reimagine the museum experience as a whole, and how cultural heritage, in particular, can be interacted with. 


\subsubsection{Augmented Reality in Cultural Heritage}

Prior to investigating the role of augmented reality in cultural heritage, this section will outline the applications, advantages, and challenges of augmented reality in general, and in cultural heritage specifically.

\subsubsection{Augmented Reality: Some Background}

Augmented reality is an enhanced digital visualization that is superimposed onto a physical environment, giving the appearance of being integrated in this environment (Milgram et al., 1994; $\mathrm{Wu}$, Lee, Chang and Liang, 2012). This integration is one of the greatest advantages of augmented reality (Kim, Kang, Choi, Choi and Hong, 2017). This dynamic interaction may be the reason augmented reality has become increasingly popular in many areas including entertainment and education.

In a systematic review of augmented reality for educational purposes, Akcayir and Akcayir (2017) reported sixty percent of augmented reality applications are built for mobile devices, twenty-four percent for desktops, and sixteen percent are created for head mounted devices specifically designed for augmented reality. The authors argue that mobile devices may be more prominent because they are more cost-effective, easier to learn to use, portable, more likely to encourage social collaboration, and built for independent operability (one's own ability to utilize the physical hardware). Furthermore, it is possible that the dynamic interaction between the physical and virtual environment may improve processing and problem-solving skills, critical thinking and on-the-spot decision making (Akcayir and Akcayir, 2017). The growing prevalence of augmented reality also demonstrates that the technology is maturing and will become easier to use. This allows wider uses for augmented reality other than entertainment, such as education, training and research.

Some of the commonly reported challenges with augmented reality are lagginess--although improvement in wireless connections have decreased this--and low sensitivity with trigger recognition (Wu, Lee, Chang and Liang, 2012). However, most studies of augmented reality have 
been short-term and some researchers suggest that more assessment protocols should be taken to analyze long-term effects of AR usage (Botden and Jakimowicz, 2009). These challenges, nevertheless, may be addressable through more human-centered design.

\subsubsection{Design and Implementation of Augmented Reality}

Developing augmented reality applications has improved by virtue of game engines such as Unity 3D and plug-ins such as Qualcomm's Vuforia. The integration of Unity 3D with the Vuforia plugin has helped novice developers build augmented reality applications fairly easily. In research as well, people can quickly prototype different applications and test it using this game engine. For example, building a mobile augmented reality application to help address obesity in children and testing its effectiveness to further iterate (Kim, Suk, Kang, Jung, Laine and Westin, 2014). With the usability of such game engines, the development of mobile augmented reality applications is more accessible to less experienced developers.

Annexing Reality, a toolkit developed by Hettiarachchi and Wigdor (2016) for Unity 3D, provides designers and developers an opportunity to match augmented virtual objects to similarly-shaped objects in one's own physical environment. A virtual object is given parameters so it attaches to a physical object of the same shape. Then each virtual object is assigned a level of preference should there be 'competition' between similarly-shaped objects. Using Kinect's depth sensor, an augmented reality gamer can grab a physical object and see the corresponding virtual object move in the simulated environment. Expert assessors who used this toolkit found it easy to learn to use and were satisfied with the tool overall. However, they did find that predicting the weight of physical objects to be difficult. Furthermore, for the gamer, erroneous head movements lead to lagging, making it less user-friendly. Nevertheless, by optimizing the availability of objects in one's everyday environment for a simulated experience, the gamer has a cost-effective and intuitive way having realistic haptic feedback in a digital environment. 


\subsubsection{Augmented Reality in Tourism}

Augmented reality applications have been used in the tourism industry to help improve the visitor experience. These applications are generally location-based and intended for guided tours (Jung and tom Dieck, 2017).

Augmented reality has successfully been integrated in creating innovative experiences in cultural heritage institutions. For example, integrated augmented reality with outdoor heritage in parks for sustainable tours (Ciolfi, 2013), incorporating natural interaction in augmented reality in museums (Kyriakou and Herman, 2018), or an interactive and context-based application in Egyptian museums (Nofal, 2013). These designs use the potential of augmented reality to increase public engagement and enhance the visitor experience.

While augmented reality has shown success in the tourism industry for destination visit and perceived usefulness of the augmented reality application, it is possible that the use of augmented reality for academic research of cultural heritage can be repurposed for scholarly use.

\section{Formative Study}

\subsection{Methodology}

The goal of this study is to discover what the current working procedures of scholars are, to identify pain points in the interactions for researching artifacts and ephemera, and to get a general understanding of potential designs for future prototypes. We hypothesized that researchers are looking for more intuitive and interactive ways of researching artifacts. We expected the interviews to provide insights into the areas cultural scholars are lacking intuitive and interactive opportunities for engaging with digital artifacts. The study received ethics approval under REB 2019-158. 
All the interviews were conducted in person and were audio-recorded. These interviews are a part of a research project being funded by the Canada Research Chair program and is being supervised by Dr. Ali Mazalek at Ryerson University. This research is happening in partnership with the Thomas Fisher Library at the University of Toronto.

\subsubsection{Data Collection}

The method for data collection used was open-ended interviewing (Yin, 2015, p. 138). Excluding demographic questions, the questions were open-ended and followed the qualitative interview format. That is, the questionnaire (see Appendix) was used by the investigator to guide the interview but the order and phrasing of the questions differed slightly depending on the context of the interview (Yin, 2015, p.142). For example, depending on how the participant answered questions, the investigator may ask about the participant's collaborative process before asking about ephemera handling. This enabled the investigator to use a more conversational style which has shown to engage the participant naturally in the interview such that they may recollect their work more easily (Yin, 2015, p. 142). Finally, data was analyzed using a five-step process: compiling, disassembling, reassembling, interpreting and concluding (Yin, 2015, p. 185). These approaches are reviewed in the data analysis.

\subsubsection{Participant Recruitment}

We recruited participants using the snowball sampling method. Participants were recruited by email. Each participant was contacted either by finding their contact in the staff and/or faculty section of a university webpage or museum or through word of mouth by colleagues in related

fields. All participants were sent a consent form to review once they had agreed to join the study through email response. They were also given a physical copy of the consent form before the start of the interview to ensure they understood the voluntariness of the study and agreed to be audiorecorded. Participants were offered a small compensation of $\$ 10$ for their participation but some participants declined as they found the study to be beneficial in and of itself. 
The inclusion criteria for participation in this study included researchers with a graduate degree or who are currently doing research as part of their graduate degree who particularly work with cultural heritage items. The exclusion criteria are researchers who are not particularly working with cultural heritage items. Demographic information was recorded including name, gender or sex, education level, email address, place of employment was recorded, however this demographic data was not used in the analysis of the interview results.

\subsubsection{Data Analysis}

The interviews were conducted and analyzed as follows:

- Interviews were audio-recorded and fully transcribed.

- Interviews were randomly selected and each participant was given an alphanumeric code.

- All questions asked were numbered to match the questionnaire.

- All answers for each participant were reorganized into a new database spreadsheet.

- The key words, points or findings of each answer were then categorized into an 'emergent themes' section for that answer.

- The themes found across various answers were summarized to find common trends.

- These steps were repeated and revised as necessary.

\subsubsection{Interview}

A total of $n=8$ participants were involved in this study. The participants comprised of 4 curators, 1 history professors, and 2 digital archaeologists. Interviews were conducted either in the participant's office or in another booked meeting room to ensure good quality audio-recording. The interviews lasted approximately between 30 to 50 minutes.

The signed copy was kept by the investigator and a copy of the consent form was given to the participant. The investigator used the questionnaire as a guide for the interview. Out of the 37 available questions, 14 interview questions and 5 demographic questions were used. Any followup questions were assigned to the corresponding interview question. 
Interview questions that overlapped with each other, were categorized and analyzed as one question. For example, questions 22 to 26, under the insights category (Appendix 2), were all placed under question 22 in the analysis. During the interview, asking each question separately proved to be redundant whereas grouping the question in one question facilitated the conversational style of the interview. The representative 'grouped' questions that were analyzed are stated below; these are the aforementioned 14 interview questions.

\subsubsection{Analyzed Interview Questions}

The 14 questions below were used to group interview answers and to analyze the data.

1) How do you define ephemera, archives, and artifacts?

2) What are the determining or motivating factors for you to visit ephemera or artifacts at an archival institution?

3) How often do you handle physical ephemera or artifacts compared to how often do you research online?

4) Can you explain what a typical research session looks like for you (in preparation of a publication or exhibition)?

5) What are the benefits of working with physical ephemera or artifacts?

6) What would you say are the top 3 problems you have when researching about ephemera through online publications?

7) How do you collaborate with other researchers while doing your own research?

8) How is the data you are working with currently presented to you? What is the cataloguing like? What are the benefits and constraints of this system?

9) How do you organize or visualize the data you are working with?

10) What kind of insights are you looking for when researching through a specific collection of ephemera?

11) How do you record your research findings? What tools do you use? This includes notetaking, data management, and the digital hardwares and softwares used. 
12) Is there a different way of working with the data that you would find more suitable for research on ephemera?

13) What is your experience with augmented reality and virtual reality?

14) Would you be interested in incorporating new or different technologies in your research process that can help simplify working with digital ephemera?

All participant's answers for each question were used to find trends in the workflows, desired insights, and common challenges during cultural heritage research. In the next section, the results will be discussed. Then, they will be interpreted in the discussion.

\subsection{Results}

After conducting our data analysis, we categorized our findings into three main sections: common practices in research, practices in tangible versus digital search, and researchers' proposed solutions for enhancing research.

\subsubsection{Research Workflow: Advantages and Disadvantages}

A heritage researcher's workflow can be categorized into: pre-research, archival research, and post-research. Each of these stages are important in the research process and tend to occur in that order.

Pre-visit: During the pre-visit phase, scholars do as much preparatory work before the archival visit. This includes, accessing various databases online, usually on a museum's, library's or another archival institution's website. The scholar will also generally contact colleagues within their network for clarification on whether certain collections are in their institution although not visible online. Here, they begin organizing their findings primarily in Excel spreadsheets, Dropbox folders and Word documents. They may also collaborate with colleagues in some respects. For example, they may email back and forth with other experts to decipher the provenance of an ephemeral item. Depending on the area of specialty, scholars may travel within Toronto to archival institutions such as the City of Toronto Archives. Many also travel overseas to the United States 
and various countries in Europe where there are vast amounts of archives. Therefore, the preresearch process is used by the scholar to gather vast data about the theme they are exploring. This is generally an exhibition or publication. It is at this stage that they decide whether visiting an archive is worthwhile and make preparations accordingly.

Archival research: Once the archival visit is decided upon, scholars tend to take an exploratory approach towards working with the cultural heritage. Here, the scholar takes an exploratory approach to working with the ephemeral items. That is, the scholar spends more time looking at individual items and analyzing each one. Here, researchers generally take photos of items in the collection with their own mobile devices and create their own database for items that are relevant to their topic of research. Here, they note details such as the box number, date, and object number of the collection. This way, they may easily refer back to the physical collection and know how to find each item easily.

When it comes to analyzing an item, cultural heritage scholars generally do not use any extra tools but instead, as one scholar mentioned, 'eyeball with expertise'. The archival visit helps the research confirm or unconfirm their hypotheses. For example, a scholar researching a photojournalist from the 1950s learned about the conditions of the artist's career at various stages of their life by the letters, photos and any other information available on the artist. Another scholar looked at cameras to analyze the propagation of its usage to the average person.

In all, scholars mentioned that when they researched, whether for publication or exhibition purposes, they were seeking insights that would help them 'tell a story'. Therefore, the purpose of studying any item of cultural heritage was not just to study the physical object but to draw implications about its social significance. That is, studying cultural heritage is for the purpose of understanding and sharing an interpretation about an aspect of society.

Post-research: Once scholars have visited the archives, they use their new-found insights to either redirect or reinforce the stories they are telling about these objects. They link the items to greater social structures and address the implications the items carried during their historical context. 
Professors will use photos of the ephemeral items in their publications. Curators will tend to use the physical objects themselves in their exhibitions. Otherwise, the research may be ongoing and lead to other archival visits for more long-term projects such as books.

In all stages of their research, researchers go back and forth between using pen and paper for notetaking, to their own laptops or desktops. The software used include Excel, Word, Dropbox, and email. Only digital archaeologists used 3D scanners.

The motivations for research varied between scholars. While most curators and both digital archaeologists claimed to work collaboratively on projects as opportunities came, the history professors and one curator reported that their work was self-driven and they picked what they researched based on their own area of specialty. Therefore, while the ways that scholars collaborate vary, the moments of collaboration are generally for the identification of mis-catalogued items, for advice, for clarification, as part of a larger project, or to get another expert's take on a topic they are less familiar with. These conversations may take place by email as they analyze the cultural heritage item or in person, about the general topic overall.

\subsubsection{Tangible Search versus Digital Search: Advantages and Disadvantages}

One of the main reported advantages of visiting archives and having the opportunity to work with physical cultural heritage pieces is that it offers scholars a more meaningful research experience. The primary motivating factor for visiting archival institutions is to find ephemeral cultural heritage that is of relevance to a participant's/ researcher's topic of study. Generally, a collection is sought out because it is unique, relevant to one's research, and/or inaccessible online. This visit may be a part of a collaborative work or a self-driven project. The visit to the archival institution was considered pivotal to most researchers and as the moment in their research that either solidifies their hypotheses or challenges it. Depending on their research specialization, researchers travelled either within the country or overseas to see these artifacts. Although central to their research, most reported that one visit was enough for their research. Whether one's work is more self-driven or collaborative seemed to be contingent on the researcher's style. Some curators preferred the 
collaborative approach and worked mainly on requested items. However, other curators were more self-driven and enjoyed an independent research process. Professors tend to be more self-driven with a few collaborations happening on occasion.

Neither historians, digital archaeologists or curators visited archives only out of curiosity or interest. However, they did mention visiting public exhibitions out of curiosity or interest. That is, while each researcher is personally motivated and curious about their work and tend to work on self-driven projects, the visits to an archival institution tend to be driven by an external motivation such as an upcoming publication or curated exhibition.

Researchers reported visiting ephemeral cultural heritage only once in the duration of one research project. Therefore, the archival visit is considered very important and researchers strategize (through researching online and contacting their network) to ensure their visit is worthwhile. A researcher contemplated the difference between tangible research and online research stating, 'I may be looking at things that I wasn't prepared for or wasn't expecting... whereas I find online that I find what I was looking for. It tends to be narrower'.

Participants stated that the majority of their research was conducted online because of ease, access, and vastness of directed search. Furthermore, it is considered to be more resourceful as it requires less time and a smaller budget. As the same participant stated, 'the 'find' function is very valuable'. That is, being able to type pointed keywords in the search function helps researchers navigate copious amounts of information in a directed and efficient way. Online research, therefore, is considered a necessary precursor to archival research. This helps prepare the scholar with as much background information about the artifact in order to prepare for the tangible search. Further, while the archival search may be copious, the tangible analysis is considered more meaningful and more rewarding for their research.

Another advantage of visiting archives is that scholars have access to all the cultural heritage that is not available online. Further, the way that the collections are organized, scholars can make uncanny connections between items that usually is not possible online. Therefore, the organization 
of the special collections can be beneficial for making unexpected discoveries. From the benefits of online and tangible research, as well as their disadvantages, scholars reported the solutions they thought would work best for their research.

\subsubsection{Reported Possible Solutions for Current Pain Points}

In terms of the kinds of solutions they proposed, scholars reported wanting more collections available online and a more improved cataloguing system. The most common proposed solution was to have more cultural heritage available online. The second proposed area for improvement was to have a more accurate cataloguing system. The third suggested solution was to have one common platform for researching cultural heritage across multiple institutions. Many found that pictures online of the object in all angles sufficed for what they were working with. As long as they had the option to zoom in and out and see the recto and verso of documents and other twodimensional ephemeral items, they found it sufficed for their pre- and post-research. For threedimensional cultural heritage items such as artifacts, they found that the physical visit is necessary if the item is indeed relevant to their research. Some agreed that three-dimensional imaging of the artifact could be helpful but contended that it would probably not replace the physical visit. One mentioned, 'I'm very comfortable dealing with materials'.

Scholars were aware of how augmented reality can be used for cultural heritage. Most only saw a use for it for exhibitive or teaching purposes. Most of them had not used augmented reality for their own work but understood how it worked. Even less experience was reported about the use of virtual reality. As one curator mentioned, 'my imagination is probably better than VR'. However, they did not see the point of augmented reality in research. When mentioning the use of augmented reality or virtual reality in their research they reported that they only saw a use for it in exhibitions or for teaching purposes but not for research. Nevertheless, the context that the augmented reality application is used matters. One curator had incorporated AR in one of their exhibitions, portraying the exhibition in 3 different time stages. She stated that the project was 'successful and beautiful' but, with a large group using one provided mobile device, the quality of the experience diminished as people had to wait a long time to use the application. However, another curator mentioned that 
using AR for her exhibitions on African art pieces would be less appropriate for her collection. She found that the AR 'looked too much like a video game' and would take away from the experience she was trying to create.

Each scholar generally said that they may not be the right person to be asking because they mentioned that the use of augmented reality for accessing archives was a good idea but they just did not see how it could apply to them.

However, scholars remain open to the possibility of such technologies because, as one representatively mentioned, 'it could be a generational thing'. Another mentioned, 'I started my career before there was an online'. Therefore, while most scholars, who are experts in their field, do not envision using a different technology to do their research, they have all shown adaptability because they now do the majority of their research online while they started their careers only researching through physical archives. The possibilities afforded by this reality are explored further in the design proposal.

\section{Design Proposal}

From our study, we found that researchers were looking for to have greater access and better information about cultural heritage. While doing large digitization projects and item-by-item recataloguing of the items were beyond the scope of this project (and beyond the scope of what most libraries also have the resources to do), we decided to start our solution by tackling a different angle of the project. We sought to make the pre-archival-visit digital search more meaningful by adding tangibility to the digital search experience and facilitating collaboration, and recommendations for easier cross platform search.

In this section, the design of an augmented reality application for researchers is discussed. The first design explores how everyday tangible objects can be used to superimpose virtual objects. The second design explores a simpler version of the first for practical purposes by introducing an 
interactive cube to the augmented reality application. For simplicity, the cultural heritage in the applications only include artifacts and not ephemera.

\subsection{Design 1}

In this prototype (Figure 1), a researcher may use their mobile device to explore artifacts in augmented space. With a mobile device, scholars can have quick access to virtual artifacts within their physical environment during their pre-archival search. That is, by pointing their mobile device's camera to a physical object, a virtual artifact of a similar shape superimposes over it so that when the scholar turns the physical object, the virtual object on the screen changes, as demonstrated in the 'annexing reality' toolkit (Hettiarachchi and Wigdor, 2016). Researchers can start using the application in one of two ways; either they can use the search function to search within the application's repository or they can enter 'camera-mode' and scan the physical objects in a room and find augmented objects similar to it. The augmented object that appears will be similar in shape to the physical object in the room. By tapping on the object, various recommended similar artifacts will appear that the user can swipe through. A description for each artifact is available. There is also the option to save artifacts into one's gallery. This way, researchers can refer to it later. Saved artifacts can also be shared with other researchers and the option to make some notes. The user interface remains simple with most of the application being in 'camera mode' and only the gallery and sharing to be separate pages. Otherwise, the features remain simple and a part of the augmented reality experience.

This is intended to help the researcher have a tangible experience of the three-dimensional visualization of an artifact. Once the model is on display, the researcher can get a description of the artifact and save it into the gallery. The researcher can also search for an artifact in the repository and use the visualization to annex to a physical object or simply view it on its own. This way, the researcher may choose between taking an exploratory approach to finding the right artifacts or taking a directed approach to finding a specific artifact. However, we were not able to implement this design because three-dimensional rendering of the artifacts on physical objects 
would require more advanced tools than what we had available. Namely, a three-dimensional camera which is not available on a mobile device. Also, with the current version of Vuforia (version 8.3.8), three-dimensional object recognition and rendering is only possible for one model at a time. Therefore, we tried to find a simpler way of providing a tangible search experience.
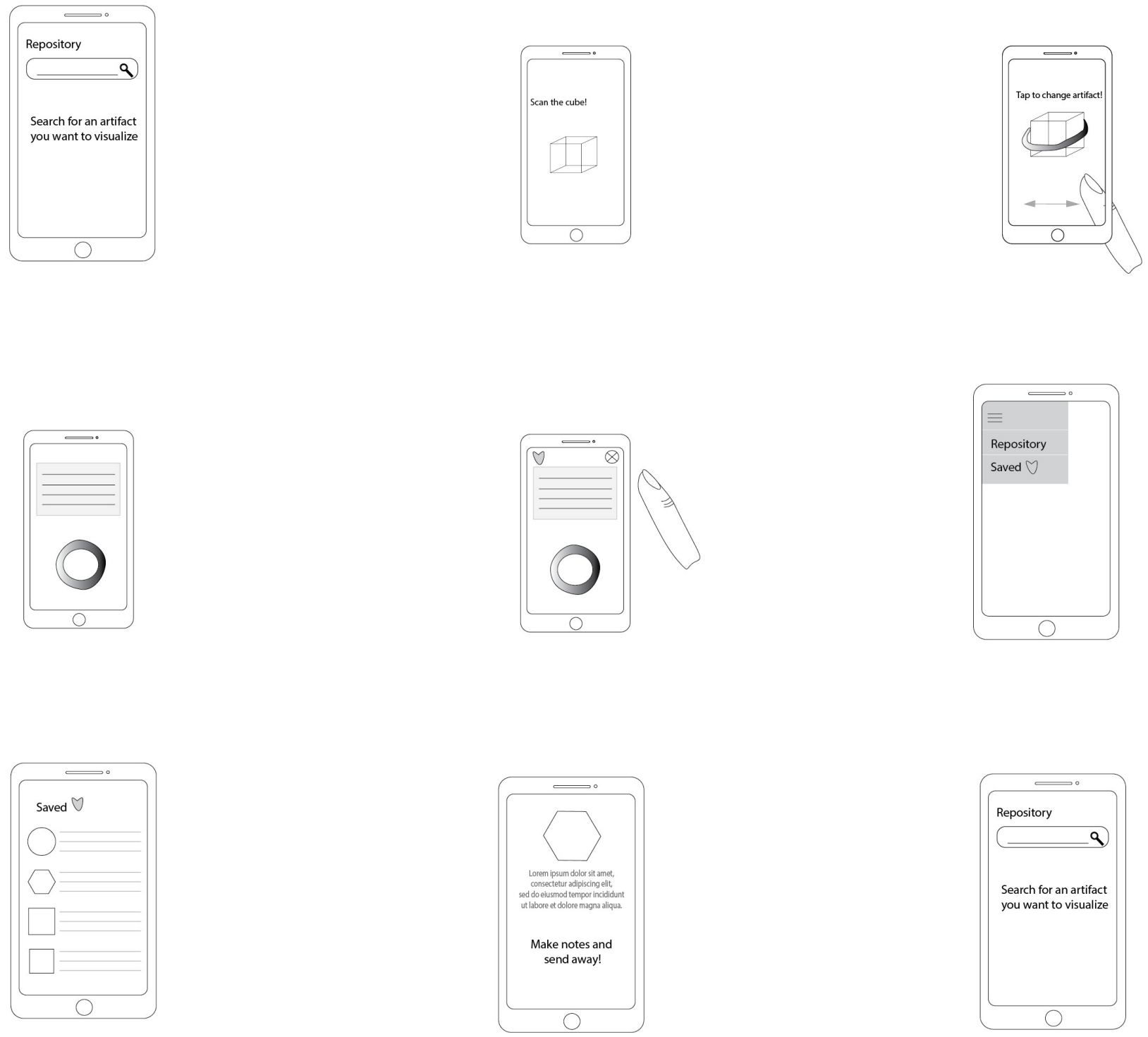

Figure 1: ‘Annexing Reality’ Style Augmented Reality Application Design. 


\subsection{Design 2}

Our second prototype (Figure 2) consists of an augmented reality application on a mobile device that is coupled with a tangible paper cube with one QR code on each of the sides. The purpose of this interactive cube is that it offers researchers a tangible experience during their digital search. This way, with the application, the camera on a mobile device detects one side of the QR code and a three-dimensional visualization of an artifact is then activated. The digital artifact covers the cube so that turning the cube around in the physical environment, turns the artifact in the virtual environment (Figure 3). Users also have the option to scroll between artifacts, get more information about an artifact, share or save the artifact, get recommendations of similar artifacts, and search through a database (Figure 4 and 5).
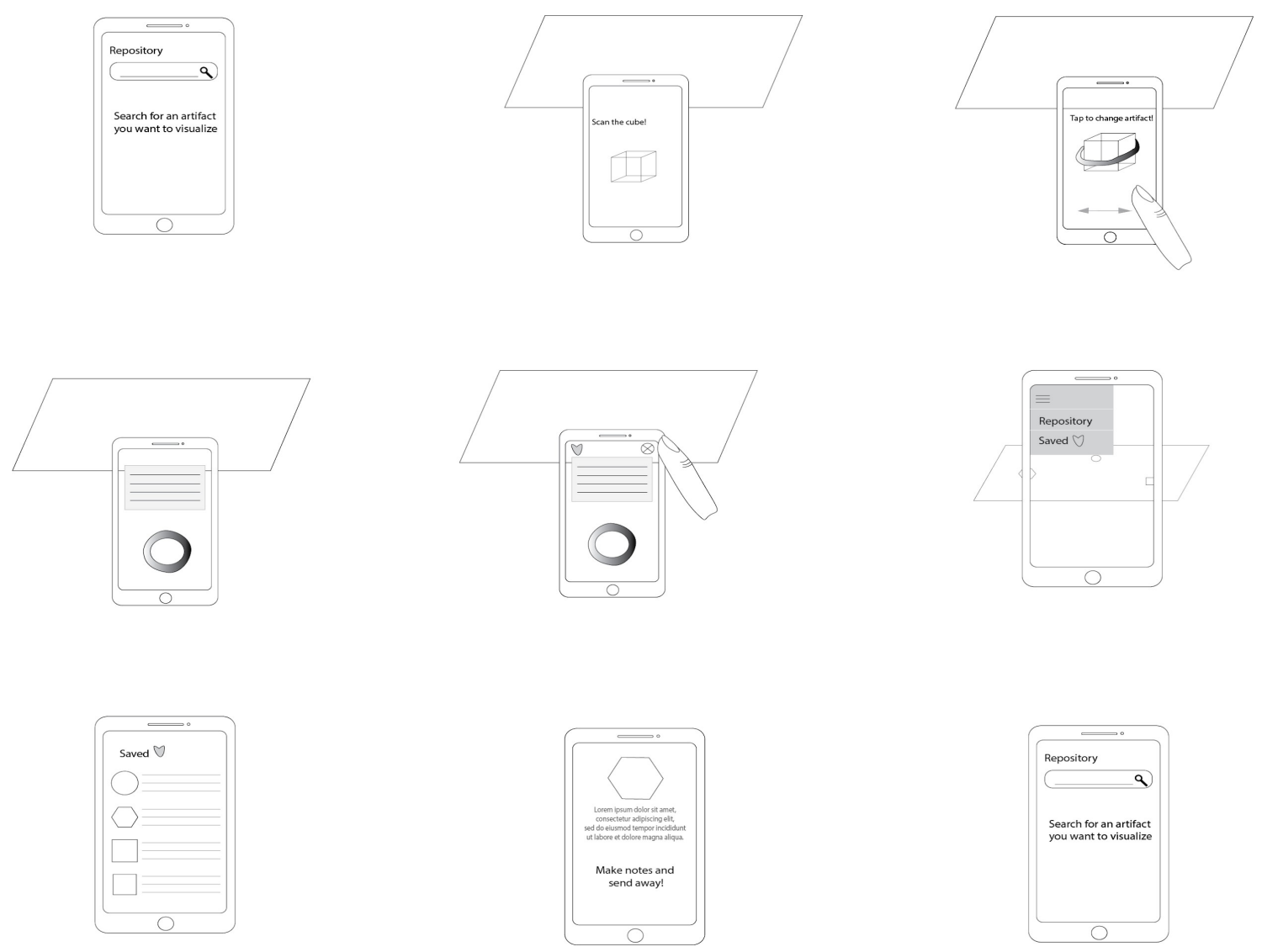

Figure 2: Interactive Cube Augmented Reality Application Design 


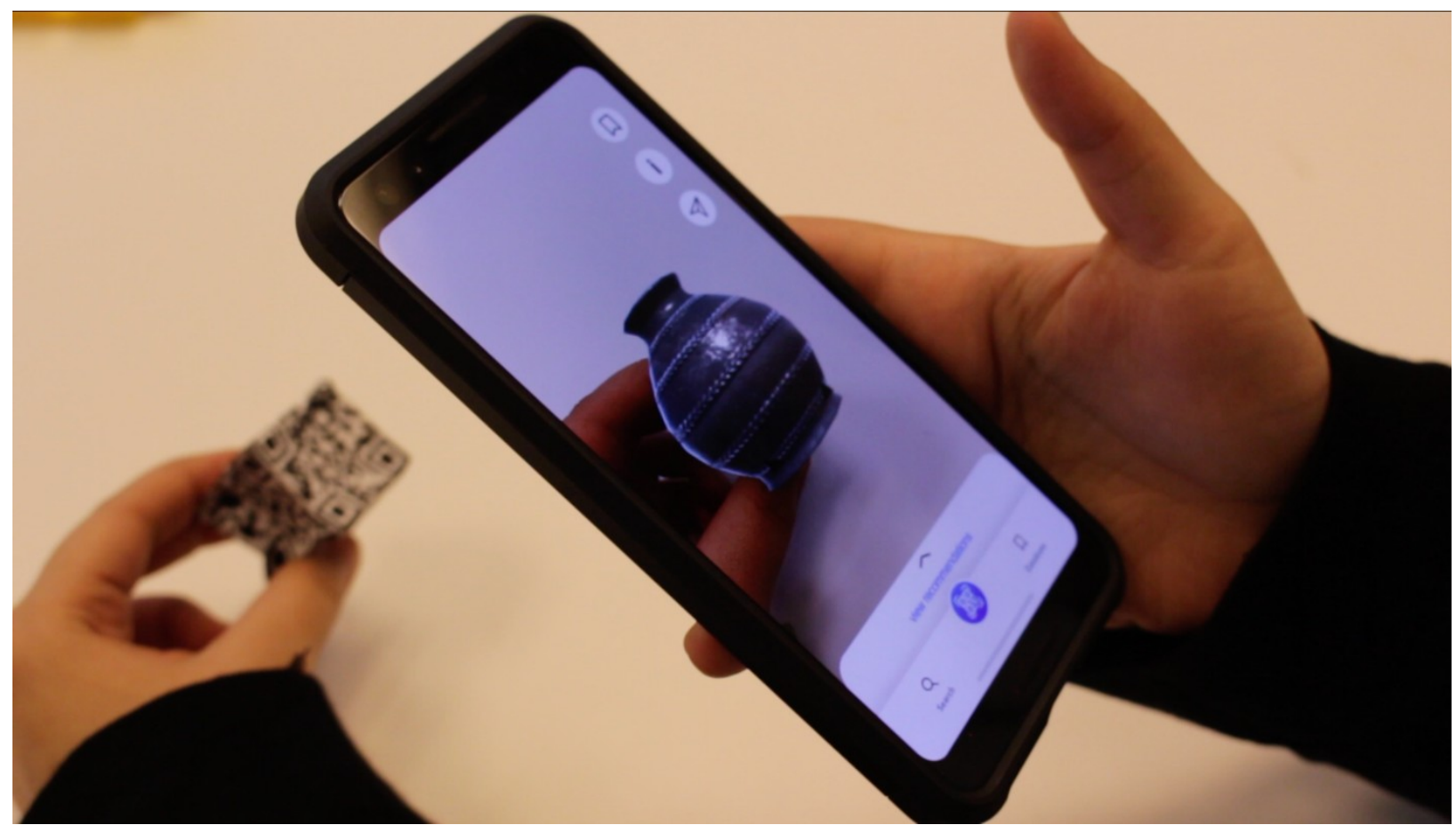

Figure 3: Interactive Cube with Artifact
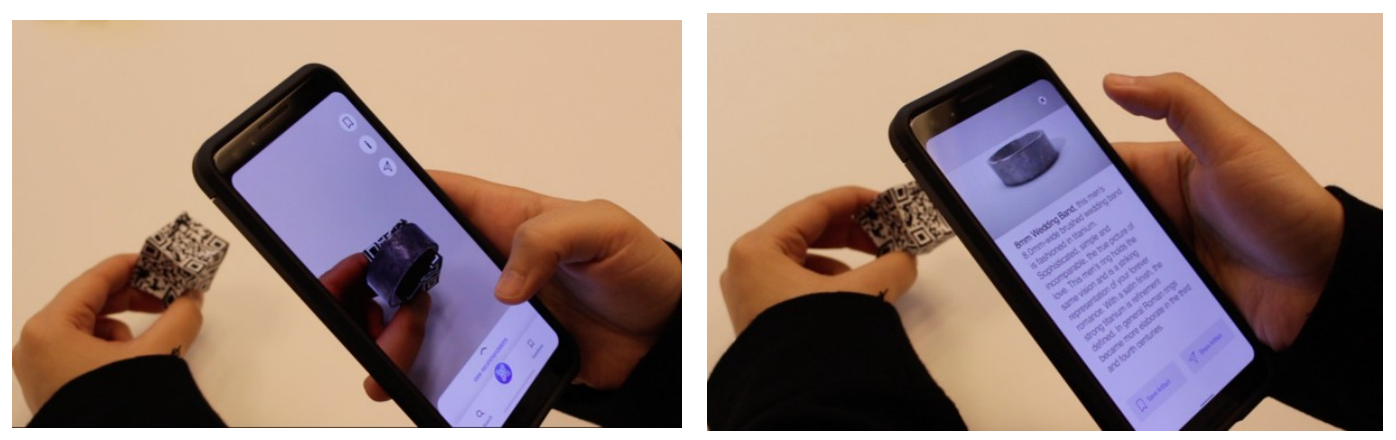

Figure 4: Artifact Switching and Description. A) the user can tap on the screen to switch between artifacts. B) each artifact has a description by selecting the 'information' button. 

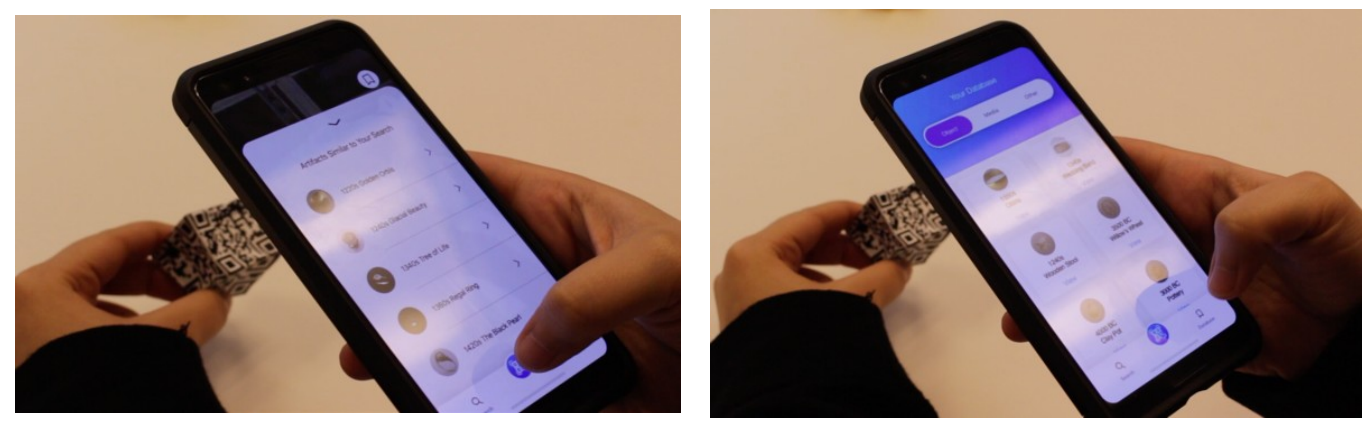

Figure 5: Interactions with Application. A) recommendations for each artifact are available. B) user can start search through the database.

The application is intended to be used by researchers during their pre-archival visit. We expect this to give them a better visualization of the cultural heritage they are researching, so that this may help them decide whether or not to take the archival visits. However, some questions we still found ourselves with were: how do we help make more cultural heritage accessible digitally? How can we help both researchers and librarians with the re-cataloguing of data? Low accessibility and inaccurate cataloguing were often mentioned as needs for improvement in the digital search.

Our next steps with this prototype involve user testing with cultural scholars and investigating whether this application would be useful for research.

\section{Future Directions}

The field of cultural heritage can be enhanced as other emerging technologies, such as augmented reality, mature. For our project, we will finalize the implementation of the interactive cube augmented reality application and conduct user studies. From these studies, we will be able to know how researchers respond to this application and whether it can be integrated in their current research. Future iterations of the augmented reality application prototype could include the archival visit in its user experience - namely, helping with accessibility and cataloguing. During their archival visit, researchers would be able to use their mobile device with the augmented reality 
application and could take a three-dimensional scan of the artifact or ephemera they are interested in evaluating. With this, they have the option of saving it to their own gallery and/or adding it to the repository. They can create their own catalogue for each artifact, write their own insightful notes and with smart recognition of these notes, the application itself could detect keywords found in the researcher's analysis and automatically create categories (or tags) to facilitate finding this artifact for future research on the multiplatform. Users can write their own artifact description and request changes in the current cataloguing of the artifact to be sent to the archivist of the library. This application could be useful for librarians as well in the digitization of their files.

\section{Conclusion}

In this paper, we investigated the value of cultural heritage and the role of augmented reality in research. We then discussed the formative study and analyzed its results. We used the study to help formulate the design of an augmented reality application that can help with cultural heritage research. Researchers in the heritage field were interviewed about their workflow, insights, and pain points during research. We found that there are 3 major stages in research, the pre-archival visit, the archival visit, and the post-archival visit. Each stage has a focus, namely, directed research in the pre-archival visit, exploratory search when visiting archives, and the post-archival search brings together the insights from the previous stages to create an exhibition, write an article, or other larger projects. While the archival visit tends to only happen once, it was considered especially valuable for artifacts (but could still be important for ephemera). Researchers noted that

working with the tangible object allowed them to draw insights about the item that is not possible through a two-dimensional, primarily visual, digital search. For future improvements (or current pain points), researchers suggested that having a greater quantity of cultural heritage available online would be helpful so that they can be easily accessed. Also, better cataloguing of the databases was also requested since researchers found that some of the information was inaccurate. Finally, some suggested to have a multiplatform website so that, through keyword searching, for example, researchers could find the same kind of ephemera or artifacts from multiplewebsites. 
The use of augmented reality, virtual reality and three-dimensional printed artifacts in museums and other heritage institutions has shown promise for enhancing the visitor experience of cultural heritage. The tourism industry has leveraged such technologies to increase interest in cultural heritage in a digital era. Augmented reality, in particular, has shown to be useful in this regard presumably because it can easily be accessed through one's mobile device (Ciolfi, 2013; Kyriakou and Herman, 2018; Nofal, 2013; Jung and tom Dieck, 2017). It is possible that augmented reality can also be applied to the scholarly research of cultural heritage. Most researchers did not see how augmented reality could be used for their own research but also noted that they began their careers only researching through archives since computers were not a part of everyday usage and the internet had not yet been created. However, they mentioned that they all relied on online research now, so even though they did not see how it could be applied, they did say they were open to seeing its application. If they could see its practical use in their own research, they said they would be open to using it in their own research.

We proposed an augmented reality application for researchers in order to help facilitate the digital part of heritage research, mainly the pre-archival visit. With an interactive cube, researchers can have a tangible experience to their digital search. This is intended to help researchers decide whether to make the archival visit, based off of their analysis of an object and the recommendations available as well as through collaborating with other researchers (by sharing found items). With user testing, we will be able to see whether this can be integrated into scholarly research.

The possibilities with augmented reality in the field of cultural heritage research are vast and offer new ways of integrating the digital and physical search experience. 


\section{References}

Adikari, S., McDonald, C., \& Campbell, J. (2013, July 21). Reframed Contexts: Design Thinking for Agile User Experience Design. Retrieved August 23, 2019, from https://link.springer.com/chapter/10.1007/978-3-642-39229-0_1

Akçayır, M., \& Akçayır, G. (2017). Advantages and challenges associated with augmented reality for education: A systematic review of the literature. Educational Research Review, 20, 1-11.

Anghelescu, H. G. (2001). A bit of history in the library attic: challenges of ephemera research. Collection management, 25(4), 61-75.

Barsom, E. Z., Graafland, M., \& Schijven, M. P. (2016). Systematic review on the effectiveness of augmented reality applications in medical training. Surgical endoscopy, 30(10), 41744183.

Benouaret, I., \& Lenne, D. (2015). Personalizing the museum experience through context-aware recommendations. In 2015 IEEE International Conference on Systems, Man, and Cybernetics (pp. 743-748). IEEE.

Boehmer, J., Jung, Y., \& Wash, R. (2015). e-Commerce Recommender Systems. The International Encyclopedia of Digital Communication and Society, 9999(9999), 1-8.

Botden, S. M., \& Jakimowicz, J. J. (2009). What is going on in augmented reality simulation in laparoscopic surgery?. Surgical endoscopy, 23(8), 1693.

Brumann, C. (2015). Cultural heritage. In International encyclopedia of the social \& behavioral sciences (pp. 414-419). Elsevier.

Bruno, F., Bruno, S., De Sensi, G., Luchi, M. L., Mancuso, S., \& Muzzupappa, M. (2010). From $3 \mathrm{D}$ reconstruction to virtual reality: A complete methodology for digital archaeological exhibition. Journal of Cultural Heritage, 11(1), 42-49. 
Chu, J. H., Clifton, P., Harley, D., Pavao, J., \& Mazalek, A. (2015). Mapping place: Supporting cultural learning through a lukasa-inspired tangible tabletop museum exhibit. In Proceedings of the Ninth International Conference on Tangible, Embedded, and Embodied Interaction (pp. 261-268). ACM.

Chung, N., Han, H., \& Joun, Y. (2015). Tourists' intention to visit a destination: The role of augmented reality (AR) application for a heritage site. Computers in Human Behavior, 50, 588-599.

Ciolfi, L., Petrelli, D., Goldberg, R., Dulake, N., Willox, M., Marshall, M., \& Caparrelli, F. (2013). Exploring historical, social and natural heritage: challenges for tangible interaction design at Sheffield General Cemetery.

Elhady, H. (2019, March 16). Top Game Engines. Retrieved from https://instabug.com/blog/game-engines/

He, Z., Wu, L., \& Li, X. (2018). When art meets tech: The role of augmented reality in enhancing museum experiences and purchase intentions. Tourism Management, 68(Complete), 127-139. doi:10.1016/j.tourman.2018.03.003

Hettiarachchi, A., \& Wigdor, D. (2016). Annexing reality: Enabling opportunistic use of everyday objects as tangible proxies in augmented reality. In Proceedings of the $2016 \mathrm{CHI}$ Conference on Human Factors in Computing Systems (pp. 1957-1967). ACM.

Huang, T. C., Chen, C. C., \& Chou, Y. W. (2016). Animating eco-education: To see, feel, and discover in an augmented reality-based experiential learning environment. Computers \& Education, 96, 72-82. 
Jones, E. (2017). The public library movement, the digital library movement, and the large-scale digitization initiative: Assumptions, intentions, and the role of the public. Information \& Culture, 52(2), 229-263. doi:http://dx.doi.org.ezproxy.lib.ryerson.ca/10.7560/IC52205

Jung, T. H., \& tom Dieck, M. C. (2017). Augmented reality, virtual reality and 3D printing for the co-creation of value for the visitor experience at cultural heritage places. Journal of Place Management and Development, 10(2), 140-151.

Kim, S. K., Kang, S. J., Choi, Y. J., Choi, M. H., \& Hong, M. (2017). Augmented-Reality Survey: from Concept to Application. KSII Transactions on Internet \& Information Systems, 11(2).

Kim, S. L., Suk, H. J., Kang, J. H., Jung, J. M., Laine, T. H., \& Westlin, J. (2014). Using Unity 3D to facilitate mobile augmented reality game development. In 2014 IEEE World Forum on Internet of Things (WF-IoT) (pp. 21-26). IEEE.

Kwan, J., Chu, J. H., Harley, D., McBride, M., \& Mazalek, A. (2016). Grasping Cultural Context through Multisensory Interactions. In Proceedings of the TEI'16: Tenth International Conference on Tangible, Embedded, and Embodied Interaction (pp. 482-487). ACM.

Kyriakou, P., \& Hermon, S. (2019). Can I Touch This? Using Natural Interaction in a Museum Augmented Reality System. Digital Applications in Archaeology and Cultural Heritage, 12, e00088.

Milgram, P., \& Kishino, F. (1994). A taxonomy of mixed reality visual displays. IEICE TRANSACTIONS on Information and Systems, 77(12), 1321-1329.

Reitsma, L., Smith, A., \& Van Den Hoven, E. (2013). Storybeads: preserving indigenous knowledge through tangible interaction design. In 2013 International conference on culture and computing (pp. 79-85). IEEE. 
Roussou, M. (2001). Immersive interactive virtual reality in the museum. Proc. of TiLE (Trends in Leisure Entertainment).

Smith, K. A. (2016). Digitizing Ephemera Reloaded: A Digitization Plan for an Art Museum Library. Art Documentation: Journal of the Art Libraries Society of North America, 35(2), 329-338.

Wu, H. K., Lee, S. W. Y., Chang, H. Y., \& Liang, J. C. (2013). Current status, opportunities and challenges of augmented reality in education. Computers \& education, 62, 41-49. 


\section{Appendix}

\section{Questionnaire}

Subject: Ephemera--a transient item that was created for limited usage but becomes a meaningful article of history to explore greater questions about culture, society and humanity as a whole.

Purpose: Discovering Content + Pain Points

- DEMOGRAPHIC:

○ Name

- Research institution/University

- Research specialization?

- Expertise - number of years as researcher/specialist?

- DEFINITION:

- Do you know what ephemera and archives are?

- How would you define both terms?

- MOTIVATION:

- [For researchers], what are the determining factors that motivate you to visit a distant library to see its ephemera?

- PROCESS: [For researchers, librarians, and metadata specialists]

- Could you give us a ratio of how often you handle physical ephemera versus how often you search online through online publications? For example, ejournals, and museum's websites

- Can you explain what a typical research session [for a paper] looks like on any given day? (Get case studies).

- When researching, are you generally looking for one specific ephemera or do you search by another category? (E.g. era, location, usage, evolution in technology) 
- If there were no limitations to how you'd research, what would a research session look like? (E.g. start with geographical map to pick location, timeline, etc.)

- What would you imagine are the benefits of working with physical ephemera?

$\circ$ What do you think are the benefits of researching digitally?

- What would you say are the top 3 problems you have when researching about ephemera through online publications?

- COLLABORATION: [For researchers]

○ How do you collaborate with other researchers while doing your own research?

- How do you discuss what you discover from literature reviews or your findings from the physical collections?

- VISUALIZATIONS: [For all]

○ [For researchers], how is the data you are working with currently presented to you? (E.g. open-source linked data vs. library's search engines).

- What are the benefits of the current publications?

- What are their constraints?

- [For librarians], if a researcher is unable to make it to your library but is interested in one of your objects, what would make it possible for them to access it remotely?

- [For metadata specialists], what is the current categorization process for the ephemera at your institution?

$\circ \quad$ [For metadata specialists], Can you break down the digitization process in steps from archives to final digital platform?

- [For all], how do you visualize the data you are working with?

- INSIGHTS: [For researchers]

- What insights are you looking for when researching through a specific collection of ephemera?

○ Do you look for more information about the context the ephemera was in? If so, what contextual information are you looking for?

○ What physical properties are important for a researcher to know--especially if they cannot access the object in person but only digitally? 
$\circ$ Are you interested in knowing the meaningfulness of the object to the original owner? The collectionist?

- How do you make the relation between a piece of ephemera and contemporary society? Through literature reviews? Discussions? Are there other means?

- TECHNOLOGY: [For researchers]

○ How do you record your research findings? This includes note-taking, database management, etc.

- What technologies are you used to using?

- E.g. Hardware: e.g. laptop and mouse, archaeological tools;

- E.g. software: Excel, MySQL, Omeka, Islandora, etc.

- How do you approach various ephemera during the digitization process?

- What are the visualizations you encounter for metadata? (E.g. digital repositories, open-source linked data visual representations, etc.)

- How have these visualizations helped your research?

- Do you have any struggles with the current visualization techniques?

- If so, what do you think could help with this process?

○ Is there a different way of working with the data that you would find more suitable for research on ephemera?

- What functions and features would you want to have that would make the tool valuable in your research?

- For example, would you want the interface to work differently? To use different kinds of technology or tools to interact with digitized ephemera?

- What is your experience with AR/VR?

○ Do you think an AR/VR experience will benefit or inhibit your research process? How do you imagine this would happen?

- Would you be interested in incorporating new or different technologies in your research process that can help simplify working with digital ephemera?

TCA-Specific Questions: [For all] 
1. [For researchers] We have a collection of postcards, coins, flyers, maps, identity cards, and letters that we're working with...

1. With more options with emerging technology, how would you ideally like to be able to interact with such ephemera digitally?

2. What kind of user experience would you want available to work with? Specifically, what kind of functions/features would help you research these special collections more easily?

3. What about when you go on exhibits? What could help you experience the ephemera more fully?

2. What would you be most interested in knowing about ephemera from the holocaust? 